\title{
Moisture Sorption Characteristics of Corn Stover and Big Bluestem
}

\author{
C. Karunanithy, ${ }^{1}$ K. Muthukumarappan, ${ }^{2}$ and A. Donepudi ${ }^{2}$ \\ ${ }^{1}$ Food and Nutrition Department, University of Wisconsin-Stout, Menomonie, WI 54751, USA \\ ${ }^{2}$ Agricultural and Biosystems Engineering Department, South Dakota State University, 1400 North Campus Drive, \\ Brookings, SD 57007, USA
}

Correspondence should be addressed to C. Karunanithy; chinnaduraik@uwstout.edu

Received 8 August 2012; Accepted 20 December 2012

Academic Editor: Yoon Y. Lee

Copyright (C) 2013 C. Karunanithy et al. This is an open access article distributed under the Creative Commons Attribution License, which permits unrestricted use, distribution, and reproduction in any medium, provided the original work is properly cited.

\begin{abstract}
Moisture content is an important feedstock quality in converting it into energy through biochemical or thermochemical platforms. Knowledge of moisture sorption relationship is useful in drying and storage to preserve the quality of feedstocks. Moisture sorption isotherms for potential feedstocks such as corn stover and big bluestem are missing. EMC values of corn stover and big bluestem were determined using static gravimetric technique with saturated salt solutions (ERH 0.12-0.89) at different temperatures (20, 30, and $40^{\circ} \mathrm{C}$ ). Depending upon the ERH values, EMC values were ranged from 8.0 to 19.6 and 8.8 to $19.2 \% \mathrm{db}$ for corn stover and big bluestem, respectively, and they followed typical type II isotherm found in food materials. Nonlinear regression was used to fit five commonly used three-parameter isotherm models (i.e., modified Oswin model, modified Halsey model, modified Chung-Pfost model, modified Henderson model, and the modified Guggenheim-Anderson-de Boer (GAB) model) to the experimental data. Modified Halsey emerged as the best model with high $F$-statistic and $R^{2}$ values with low $E_{m}$ and $E_{s}$ and fairly random scattered residual plot for corn stover and big bluestem. These models can be used to predict the equilibrium moisture content of these feedstocks starting from harvesting, drying, preprocessing, transportation, storage, and conversion.
\end{abstract}

\section{Introduction}

The search for a renewable fuel resource has become a global priority due to obvious reasons such as declining fossil fuel resources and economic and environmental concerns. According to Demirbas [1], lignocellulosic biomass appears to be an attractive feedstock due to its renewability, positive environmental impacts resulting in no net release of carbon dioxide, and very low sulfur content, and they are cheap (compared to corn/sugarcane) and abundant [2]. Corn stover is considered as one of the potential feedstock and most studied materials towards biofuel too. Perlack et al. [3] estimated that approximately 256 million dry tons of corn stover will be available for conversion into fuel in the year 2030 due to collection technologies improvement and a steady yield increase. Several studies have shown that big bluestem has a great potential as a feedstock in the biofuel arena harvest years [4-6]. Moreover, the United States Department of Energy has also listed big bluestem as one of the herbaceous energy crops.
Based on the previous facts, corn stover and big bluestem were selected for this study.

Moisture content is an important attribute of feedstocks in converting them in biochemical or thermochemical platforms into biofuels or bio-oil. Moisture content has a strong influence not only on harvesting and preprocessing/grinding but also on transportation, storage, conversion/processing, and the resultant products. There is always a trade-off between the feedstock production and its moisture content; for example, early harvest requires high drying cost [7]. According to Igathinathane et al. [8], safe storage and preprocessing of feedstock are important operations in supplying them to biorefineries. Feedstock is expected to be stored in ambient atmospheric conditions in an open field or in an enclosure due to bulky nature of it. The quality of stored feedstock is influenced by biological, microbiological, and organochemical reactions of the feedstock [9]. Deterioration of the feedstock depends on the moisture content and the types of storage. Nurmi [10] has reported that one of the 
challenging tasks in biomass harvesting is how to manage the storage of the feedstock. Several studies have revealed that the long-term storage results in dry matter loss, reduction in energy content, and causes health risk for the workers. In order to store the feedstock for long-term period, the moisture content should be below $17.65 \% \mathrm{db}$ [7]. Feedstocks are subjected to different relative humidity $(\mathrm{RH})$ and temperatures during harvesting, preprocessing, transportation, and storage in a wide variety of climates. Knowledge of the relationship between the temperature and $\mathrm{RH}$ of air is useful in selection of correct drying and storage operations to preserve the quality of feedstocks.

Most of the feedstocks are hygroscopic in nature, meaning that they may adsorb and desorb the moisture from surrounding atmosphere $[11,12]$ depending upon the environmental conditions. When the internal vapor pressure of the feedstock is equal to the vapor pressure of the surrounding air, the moisture content of the material represents the equilibrium moisture content (EMC). The internal vapor pressure depends upon the surrounding environment, that is, the temperature and $\mathrm{RH}$, the characteristics of feedstock. EMC is useful to determine whether a feedstock will gain or lose moisture under a given set of temperature and $\mathrm{RH}$ conditions. Different feedstocks have different EMCs depending upon the temperature and $\mathrm{RH}$ of the environment as well as species, variety, maturity [13-15], porosity and microstructure [16], specific surface area [17], and amount of extractives and strength of feedstock/wood [18]. Recently, Jorgenson et al. [19] reported the monthly average EMC of woody biomass in the range of $4.9-21 \% \mathrm{db}$ depending upon the locations (Fargo, North Dakota; Boulder, Colorado; Olympia, Washington; Phoenix, Arizona) within the US.

EMC can be determined through either static or dynamic method. In the static method, saturated salt solutions or acids of different concentrations are used for obtaining different ERH in a closed chamber. In the dynamic method, the various RHs are obtained by mixing fully dried air and fully saturated air at required proportions, or by conditioning the air by mixing with water vapor appropriately. In dynamic method, continuous recording of change in weight is technically more complicated than the static one. However, the main advantage of the dynamic method is that the sample reaches equilibrium more rapidly than with the static method. The principal static methods are gravimetric, manometric, and hygrometric. According to Aviara et al. [20], gravimetric technique has several advantages over the manometric and hygrometric techniques, and these are ability to determine the exact dry weight of the sample, minimization of temperature fluctuation between samples and their surroundings, recording the weight change in equilibrium with the respective water vapor pressures, and achieving hygroscopic and thermal equilibrium between samples and water vapor source. The advantage of the static method is its ability to maintain constant conditions easily [21-23]. Among static methods, gravimetric technique has been considered preferable/reliable to obtain complete sorption isotherms [20, 24] and has been recommended as the standard method [25]. Sometimes the weighing process may induce measuring errors [26], and mold may easily develop on samples in the high RH environment [27]. Therefore, these points should be addressed adequately while conducting an experiment. The method selection depends on the types of material, dynamic method is more suitable for pellets/briquettes, and static materials are suitable for powdery materials.

Early equilibrium moisture relations of biomass/feedstocks are limited and found for prairie hay, red clover hay, oat straw, and alfalfa hay in the 1940s [28, 29]. Due to high attention in biofuel research, once again researchers have started looking into EMC of different feedstocks such as wheat straw [30], pine [18], selected corn stover components [31], flax straw, hemp stalk, and reed canary grass [12], willow [32], amaranth stem [33], and miscanthus leaves and stem [7], and briquettes or pellets made from cotton stalk and sawmill waste [11], switchgrass [34], softwood [35], peanut hull [36], sorghum stalk, corn stover, wheat straw, and big bluestem [37]. Moisture sorption isotherms describe the relationship between the equilibrium RH (ERH) and the EMC at constant temperatures and pressures [38]. Several researchers have reviewed the suitability of isotherm models for various biological materials and concluded that no "universal model" adequately describes sorption behaviors over a broad range of temperature and RH [39, 40]. Therefore, for a specific feedstock, there is need to search for the most appropriate EMC/ERH equation [31, 39, 41, 42]. No literature on corn stover and big bluestem moisture sorption isotherm was found. However, Igathinathane et al. [31] studied EMC of selected corn stover components such as corn leaf, stalk skin, and stalk pith and estimated EMC of corn stalk based on their proportions. Recently, Theerarattananoon et al. [37] reported the EMC of pellets made from big bluestem, and they have not evaluated different moisture sorption isotherms. Therefore, the objectives of this study are to determine the moisture adsorption data of corn stover and big bluestem at different temperatures $\left(20-40^{\circ} \mathrm{C}\right)$ and to evaluate the suitability of commonly used isotherm equations for predicting the EMC of these feedstocks at different ERHs.

\section{Materials and Methods}

2.1. Sample Preparation and Characterization. Corn stover and big bluestem were obtained from local farms (Brookings, SD, USA) and ground in a hammer mill (Speedy Jr, Winona Attrition Mill Co, MN) using $4 \mathrm{~mm}$ sieve. The ground feedstock was stored in sealed bins $(0.68 \mathrm{~m}$ height and $0.47 \mathrm{~m}$ diameter $)$ at room temperature $\left(20 \pm 1^{\circ} \mathrm{C}\right)$ until needed. The initial moisture content of the feedstocks was determined based on ASABE Standard S358.2 for forage moisture determination [53]. The amounts of extractives in these feedstocks were determined following NREL protocol [54].

2.2. Experimental Procedure. The moisture adsorption characteristics of feedstocks were determined at three different temperatures $\left(20,30\right.$, and $\left.40^{\circ} \mathrm{C}\right)$ and at various $\mathrm{RH}$ conditions ranging from $12 \%$ to $89 \%$ using static gravimetric method (since feedstocks were in powdery form). Relative humidity conditions were maintained using different saturated salt 
TABLE 1: ERH of the saturated salt solutions used in this study.

\begin{tabular}{|c|c|c|c|c|}
\hline \multirow{2}{*}{ Saturated salt solution } & \multirow{2}{*}{ Chemical formula } & \multicolumn{3}{|c|}{ ERH (decimal) } \\
\hline & & $20^{\circ} \mathrm{C}$ & $30^{\circ} \mathrm{C}$ & $40^{\circ} \mathrm{C}$ \\
\hline Lithium chloride & $\mathrm{LiCl}$ & 0.126 & 0.120 & 0.118 \\
\hline Magnesium chloride & $\mathrm{MgCl}_{2}$ & 0.330 & 0.322 & 0.310 \\
\hline Potassium carbonate & $\mathrm{K}_{2} \mathrm{CO}_{3}$ & 0.451 & 0.434 & 0.420 \\
\hline Sodium bromide & $\mathrm{NaBr}$ & 0.591 & 0.573 & 0.560 \\
\hline Sodium chloride & $\mathrm{NaCl}$ & 0.752 & 0.740 & 0.730 \\
\hline Potassium chloride & $\mathrm{KCl}$ & 0.853 & 0.830 & 0.821 \\
\hline Barium chloride & $\mathrm{BaCl}$ & - & 0.890 & - \\
\hline Potassium nitrate & $\mathrm{KNO}_{3}$ & - & - & 0.893 \\
\hline
\end{tabular}

solutions which could give the respective humidity conditions at different temperatures. Various salt solutions and the experimental conditions maintained during this experiment are summarized in Table 1. ERH values were verified using a hygrometer (S 90191, Control Company, and Friendswood, TX, USA) and compared with the literature values [5557]. The differences in the measured and the literature ERH values were negligible. The prepared saturated salt solutions and the weighed feedstock samples $(0.5 \mathrm{~g})$ in the aluminum cups were kept in the desiccators, which were sealed tightly using wax. Nalgene autoclavable plastic desiccators, with a $150 \mathrm{~mm}$ inner diameter and a $149 \mathrm{~mm}$ height, were used to provide the required environments. The lower portions of the desiccators, separated from the headspace by $140 \mathrm{~mm}$ aluminum plates, contained the specific salt solutions that had been prepared with distilled water. The salts used for preparing saturated solutions were of pure laboratory grade (Acros organics, NJ, USA). These desiccators were placed in the Fisher isotemp mechanical convection oven (Model 838F, Fisher Scientific, USA) and then exposed to varying temperatures. The change in moisture contents was observed by weighing the feedstock samples at regular intervals by taking them out (the room was also maintained the same temperature of the oven) and continued until there was no difference among the consecutive weights. In order to observe the experimental errors, the feedstock moisture readings were measured in triplicates.

2.3. Moisture Sorption Model Selection. Numerous models have been suggested in the literature to describe the relationship between EMC and ERH of biomaterials. In the late 1980s, Van den Berg [58] and Chen and Morey [39] listed the following five requirements for EMC equations: (1) the experimental curve should be described mathematically for practical applications such as drying and storing; (2) the equation should have a relatively simple form with a limited number of parameters; (3) the parameters should have a physical significance; (4) the parameters should include temperature dependence; (5) the equation should be able to correct for the influence of hysteresis. Several researchers have evaluated and found that no perfect model exists for describing sorption isotherms of biomaterials based on these criteria. Pfost et al. [59] used standard error of estimate as a criterion and compared the fit of five EMC/ERH models (with three and four parameters) to the published maize EMC data. They found that the residuals of the four-parameter equations were not significantly lower than those of the three-parameter equations. Further, it is easier to fit and use three-parameter equations without relying on tables or charts. Based on the results of this study, modified Henderson equation, modified Oswin equation, modified Chung-Pfost equation, and modified Halsey equation were adopted in ASAE standard D245.5 [60]. Most of the researchers, who studied different feedstocks such as wheat straw, selected components of corn stover, miscanthus, flax straw, hemp stalks, reed canary grass, and switchgrass pellets, used these four-three parameters equations. The Guggenheim-Anderson-deBoer (GAB) model has been recommended as the standard model for use in food laboratories in Europe [61] and the USA [62]. The temperature term was not incorporated in the GAB model; however, Jayas and Mazza [63] have incorporated the effect of temperature and developed a modified GAB model. The previous five moisture sorption models (Table 2) were selected for evaluation based on the facts presented earlier.

2.4. Analysis of Data and Model Evaluation. Parameter estimates of the models listed in Table 2 were determined with nonlinear regression procedure, using PROC NLIN of SAS version 9.2 (SAS Institute Inc, Cary, NC). The nonlinear regression procedure minimized the sum of squares of deviation between the predicted and observed isotherm data in a series of iterations to solve the model. The NLIN procedure used the Gauss-Newton method to solve the models. Input data to the NLIN procedure were a series of temperature, ERH, and corresponding EMC values for corn stover and big bluestem. The goodness of fit of each model was evaluated using performance/statistical parameters for nonlinear models, such as mean relative percent error $\left(E_{m}\right)$, standard error $\left(E_{s}\right)(\% \mathrm{db})$, coefficient of determination $\left(R^{2}\right)$, and $F$-statistic values. The $F$-statistic was directly obtained from the SAS output, and $E_{m}, E_{s}$, and $R^{2}$ were calculated using

$$
E_{m}=\sum \frac{100}{N} \frac{(Y-\widehat{Y})}{Y}
$$


TABLE 2: The five most commonly used three-parameter isotherm equations for calculation of the equilibrium moisture content (EMC).

\begin{tabular}{lc}
\hline Model name & Equation \\
\hline Modified Oswin & $M=(A+B T)\left[\frac{\mathrm{RH}}{1-\mathrm{RH}}\right]^{1 / C}$ \\
Modified Halsey & $M=\left[\frac{-\exp (A+B T)}{\ln (\mathrm{RH})}\right]^{1 / C}$ \\
Modified Henderson & $M=\left[\frac{\ln (1-\mathrm{RH})}{-A(T+B)}\right]^{1 / C}$ \\
Modified Chung-Pfost & $M=\frac{-1}{C} \ln \left[\frac{\ln (\mathrm{RH})(T+B)}{-A}\right]$ \\
Modified GAB & $M=\frac{A(C / T) B \mathrm{RH}}{(1-B \mathrm{RH})(1-B \mathrm{RH}+(C / T) B \mathrm{RH})}$ \\
\hline
\end{tabular}

$M$ : moisture content, (\% db); RH: relative humidity (decimal); $T$ : temperature ${ }^{\circ} \mathrm{C} ; A, B$, and $C$ : constants specific to each equation.

$$
\begin{aligned}
& E_{s}=\sqrt{\frac{\sum(Y-\widehat{Y})^{2}}{\mathrm{df}}}, \\
& R^{2}=1-\frac{\text { Error } S S}{\text { Total } S S}
\end{aligned}
$$

where $Y$ and $\widehat{Y}$ are the measured and predicted equilibrium moisture contents in $\%(\mathrm{db}), N$ is the number of data points, and $\mathrm{df}$ is degree of freedom.

\section{Results and Discussion}

3.1. Observed EMC of Corn Stover and Big Bluestem. The experimental EMC values obtained for corn stover and big bluestem at various ERH and temperatures are shown in Figure 1. The plotted isotherms of corn stover and big bluestem followed type II isotherms for all three temperatures $[7,23]$. Type II isotherms are more common in food materials, where an increase in temperature reduces the EMC. This EMC-reducing effect of the increased temperatures is in agreement with studies on various feedstocks [7, 12, 30, $31,43]$ and pellets made from different feedstocks [11, 3437]. The highest temperature $\left(40^{\circ} \mathrm{C}\right)$ and the lowest ERH (0.12) combination produced the minimum EMC values, and the lowest temperature $\left(20^{\circ} \mathrm{C}\right)$ and the highest ERH (0.89) combination produced the maximum EMC values for the feedstocks studied. Similar trends were reported for other feedstocks such as wheat straw [30], red clover leaves and stems [43], corn leaf, corn stalk skin and corn stalk pith [31], flax straw, hemp stalks, and reed canary grass [12], flax fibre [44-46], and miscanthus [7]. The observed minimum and maximum EMC values were 8.0 and 8.8 and 19.6 and $19.2 \%$ $\mathrm{db}$ for corn stover and big bluestem, respectively. The higher EMC values of these two feedstocks were lower than that of switchgrass $(20.8 \% \mathrm{db})$ and prairie cord grass $(21 \% \mathrm{db})$ [64]. Recently, Brown [65] reported that the typical EMC of biomass would be above $33.3 \% \mathrm{db}$ if the $\mathrm{RH}$ exceeds $90 \%-$ 95\%. Considering this criterion, the feedstocks used in this study also confirm it; that is, maximum $\mathrm{RH}$ was $89 \%$ and the
EMC was far lower than $33.3 \%$ db. Yan et al. [66] reported an EMC of $15.6 \% \mathrm{db}$ for loblolly pine at a temperature of $30^{\circ} \mathrm{C}$ with $\mathrm{RH}$ of $83.6 \%$, and this value was very close to 15.5 and $15.8 \% \mathrm{db}$, respectively, for corn stover and big bluestem. At $20^{\circ} \mathrm{C}$ and $90 \% \mathrm{RH}$, corn stover had a higher EMC than that of big bluestem, whereas at 30 and $40^{\circ} \mathrm{C}$, big bluestem had a higher EMC than that of corn stover as evident from Figure 1. The EMC of corn stover in the present study was higher at lower range of ERH (0.12-0.50) when compared to corn leaf, stalk skin, and stalk pith [31], whereas the selected components of corn stover had a higher EMC at higher range of ERH ( $>0.5)$ than that of corn stover.

EMC values of different feedstocks and pellets made from different feedstocks were summarized in Table 3 for easy comparison. By comparing Figure 1 and Table 3, the present study EMC values for corn stover and big bluestem were higher at an ERH of 0.35 than that of other feedstocks. However, EMC values were well within the range of other feedstocks at ERH of 0.75 and 0.90 as listed in Table 3. EMC values for corn stover and big bluestem can be interpolated for $25^{\circ} \mathrm{C}$ using 20 and $30^{\circ} \mathrm{C}$ values. Interpolated $\left(25^{\circ} \mathrm{C}\right) \mathrm{EMC}$ values for corn stover and big bluestem were of 11.8 and 14.6 and 10.5 and $14.5 \% \mathrm{db}$ with ERH of 0.35 and 0.75 , respectively. These feedstocks had higher EMC values than that of pellets made from these feedstocks as reported by Theerarattananoon et al. [37]. Possible reasons for differences in EMC values might be due to high surface area of feedstocks [17], high strength of pellets [18], reactions during pelleting process due to high moisture and temperature [9], and feedstock geometry, morphology, and chemical composition including lignin content [46]. Amount of extractives varied from 8.5 to $12.5 \%$ and 12.5 to $19.2 \%$ for corn stover and big bluestem, respectively. There was no definite trend between amount of extractives and observed EMCs at different $\mathrm{RH}$ and temperatures. In general, common feedstocks starting from wheat straw to miscanthus had higher EMC values than that of natural fibres, wood, and pellets at $25^{\circ} \mathrm{C}$ with over the range of ERH as evident from Table 3.

3.2. Isotherms Fitting and Evaluation. Most researchers used the values of $E_{m}$ and $E_{s}$ to judge the adequacy of the models 
TABLE 3: EMC (\% db) of different feedstocks and pellets found in literature.

\begin{tabular}{|c|c|c|c|c|c|c|c|c|c|c|}
\hline \multirow{4}{*}{ Feedstocks } & \multicolumn{9}{|c|}{ Temperature, ${ }^{\circ} \mathrm{C}$} & \multirow{4}{*}{ References } \\
\hline & \multicolumn{3}{|c|}{15} & \multirow{2}{*}{\multicolumn{3}{|c|}{$\begin{array}{c}25 \\
\text { ERH }\end{array}$}} & \multirow{2}{*}{\multicolumn{3}{|c|}{35}} & \\
\hline & & & & & & & & & & \\
\hline & 0.35 & 0.75 & 0.90 & 0.35 & 0.75 & 0.90 & 0.35 & 0.75 & 0.90 & \\
\hline Wheat straw & 8.0 & 14.5 & 28.5 & 7.5 & 14.0 & 27.0 & 7.0 & 11.5 & 24.0 & Duggal and Muir, 1981 [30] \\
\hline Red clover leaves & & & & 5.8 & 9.9 & 12.9 & 5.3 & 8.7 & 10.9 & Stencl and Homola, 2000 [43] \\
\hline Red clover stems & & & & 13.6 & 17.0 & 21.2 & 11.7 & 15.6 & 18.3 & Stencl and Homola, 2000 [43] \\
\hline Flax straw & 9.5 & 15.0 & 25.5 & 9.0 & 14.5 & 24.0 & & & & Nilsson et al., 2005 [12] \\
\hline Hemp stalk & 9.0 & 14.5 & 22.5 & 7.0 & 13.0 & 21.0 & & & & Nilsson et al., 2005 [12] \\
\hline Reed canary grass & 10.0 & 15.0 & 22.0 & 7.0 & 13.5 & 20.0 & & & & Nilsson et al., 2005 [12] \\
\hline Amaranth stem & 9.9 & 16.2 & 25.8 & 8.5 & 13.7 & 22.8 & & & & Stencl et al., 2010 [33] \\
\hline Corn leaves & & & & 7.5 & 15.0 & 28.1 & 5.7 & 12.7 & 22.7 & Igathinathane et al., 2005 [31] \\
\hline Corn stalk skin & & & & 6.5 & 15.1 & 27.0 & 5.4 & 13.5 & 20.7 & Igathinathane et al., 2005 [31] \\
\hline Corn stalk pith & & & & 5.8 & 13.1 & 37.6 & 3.6 & 10.9 & 24.0 & Igathinathane et al., 2005 [31] \\
\hline Corn stalk & & & & 6.4 & 14.6 & 29.8 & 4.9 & 12.8 & 21.6 & Igathinathane et al., 2005 [31] \\
\hline Miscanthus leaves & & & & 9.0 & 18.0 & 31.0 & & & & Arabhosseini et al., 2010 [7] \\
\hline Miscanthus stem & & & & 8.5 & 16.5 & 30.0 & & & & Arabhosseini et al., 2010 [7] \\
\hline \multicolumn{11}{|l|}{ Natural fibres } \\
\hline Flax fibre & 5.0 & 10.0 & 15.0 & 4.0 & 9.0 & 14.0 & & & & Hill et al., 2009; $2010[44,45]$; Xie et al., 2011a [46] \\
\hline Jute fibre & & & & $6.0-6.5$ & $12.0-13.5$ & $18-19$ & & & & Hill et al., 2009 [44]; Xie et al., 2011a [46] \\
\hline Hemp fibre & & & & 5.0 & 11.5 & 18.3 & & & & Xie et al., 2011a [46] \\
\hline Sisal fibre & & & & 5.5 & 12.0 & 18.8 & & & & Xie et al., 2011a [46] \\
\hline \multicolumn{11}{|l|}{ Wood } \\
\hline Sapwood of Scots Pine & & & & $5.5-7.5$ & $12.5-15.0$ & $18.0-20.2$ & & & & Xie et al., 2010; 2011b $[47,48]$ \\
\hline Maple wood ${ }^{*}$ & & & & 6.2 & 12.5 & 18.0 & & & & Papadopoulos, 2005 [49] \\
\hline Elm wood & & & & 6.0 & 12.0 & 17.5 & & & & Papadopoulos, 2005 [49] \\
\hline Balsa wood* & & & & 5.5 & 12.0 & 19.0 & & & & Wimmer and Schmid, $2010[50]$ \\
\hline Sapwood/softwood* & & & & $6.5-7.0$ & $13.0-13.5$ & $17.0-18.0$ & & & & $\begin{array}{l}\text { Papadopoulos and Hill, } 2003 \text { [51]; Mantanis and } \\
\text { Papadopoulos, } 2010 \text { [52] }\end{array}$ \\
\hline \multicolumn{11}{|l|}{ Pellets from } \\
\hline Switchgrass & & & & 7.5 & 11.5 & 15.0 & & & & Colley et al., 2007 [34] \\
\hline Peanut hull & & & & 9.0 & 14.0 & 22.5 & & & & Fasina, 2008 [36] \\
\hline Corn stover & & & & 9.5 & 14.0 & 20.5 & & & & Theerarattananoon et al., 2011 [37] \\
\hline Wheat straw & & & & 9.5 & 13.0 & 20.0 & & & & Theerarattananoon et al., 2011 [37] \\
\hline Big bluestem & & & & 9.8 & 14.0 & 20.0 & & & & Theerarattananoon et al., 2011 [37] \\
\hline Sorghum stalk & & & & 10.0 & 15.0 & 21.0 & & & & Theerarattananoon et al., 2011 [37] \\
\hline
\end{tabular}

Values were extracted either from table or figure from respective references.

${ }^{*}$ At $20^{\circ} \mathrm{C}$.

to represent the relationship $[7,12,31,33,34,39,67,68]$. Lower values of $E_{m}$ and $E_{s}$ indicate the better fit of the model compared with the other models. Chen and Morey [39] showed that low values of $E_{m}$ and $E_{s}$ were not sufficient criteria for evaluating the goodness of fit of isotherm equations; in addition, they recommended the use of residual plots. Accordingly, the residuals of EMC were plotted against independent variable (ERH) values and evaluated visually for randomness or pattern. A model was considered acceptable if the residuals were uniformly scattered about independent variable in $x$-axis, showing no systematic distribution or clear pattern of dependent variable residuals in the positive and negative directions of the $y$-axis. When a residual plot of a model indicated a systematic distribution or clear pattern, the model was not accepted $[38,39]$. In this study, if a model has relatively small error terms (i.e., $E_{s}$ and $E_{m}$ ), high $F$ statistic and $R^{2}$ values, and residual plots with randomly scattered points $[31,33,34,67]$, then it was considered as good/acceptable model.

The fitted isotherm constants and parameters indicating goodness of model fit are listed in Table 4. Out of five models used, modified GAB model did not fit well with 
TABLE 4: Fitted isotherm parameters for corn stover and big bluestem.

\begin{tabular}{|c|c|c|c|c|c|c|c|c|}
\hline \multirow{2}{*}{ Equation } & \multicolumn{3}{|c|}{ Constants } & \multicolumn{5}{|c|}{ Performance/statistical parameters } \\
\hline & $A$ & $B$ & C & $E_{m}$ & $E_{s}$ & $F$ & $R^{2}$ & Residual \\
\hline \multicolumn{9}{|l|}{ Corn stover } \\
\hline Modified Oswin & 15.41 & -0.099 & 6.447 & 0.2476 & 1.455 & 1599 & 0.988 & Random \\
\hline Modified Halsey & 13.04 & -0.0402 & 4.8927 & 0.1310 & 1.384 & 1770 & 0.989 & Random \\
\hline Modified Henderson & $1.604 \times 10^{-7}$ & 2.9404 & 4.6443 & 0.3754 & 1.616 & 1292 & 0.986 & Systematic \\
\hline Modified Chung-Pfost & 2165 & -1.4086 & 0.3834 & 0.0977 & 1.462 & 84 & 0.745 & Random \\
\hline Modified GAB & 4.8372 & 2.011 & 1.177 & 3710 & 11.28 & 8 & 0.298 & Systematic \\
\hline \multicolumn{9}{|l|}{ Big bluestem } \\
\hline Modified Oswin & 15.7704 & -0.1270 & 5.2686 & 0.6668 & 1.206 & 2269 & 0.992 & Systematic \\
\hline Modified Halsey & 10.5023 & -0.0427 & 3.9133 & 0.3607 & 1.062 & 2939 & 0.994 & Random \\
\hline Modified Henderson & $2.63 \times 10^{-6}$ & -0.3569 & 3.6383 & 0.9798 & 1.438 & 1515 & 0.988 & Systematic \\
\hline Modified Chung-Pfost & 776.6 & -3.7506 & 0.3184 & 0.3684 & 1.261 & 165 & 0.853 & Systematic \\
\hline Modified GAB & 4.1221 & 2.0197 & 1.3465 & 2688 & 11.12 & 7.95 & 0.295 & Systematic \\
\hline
\end{tabular}

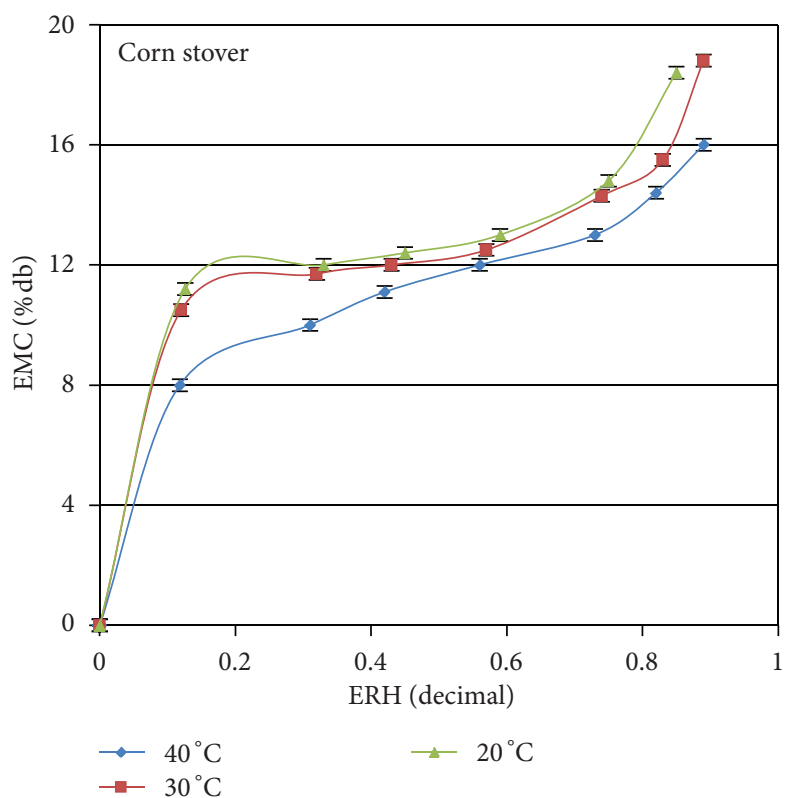

(a)

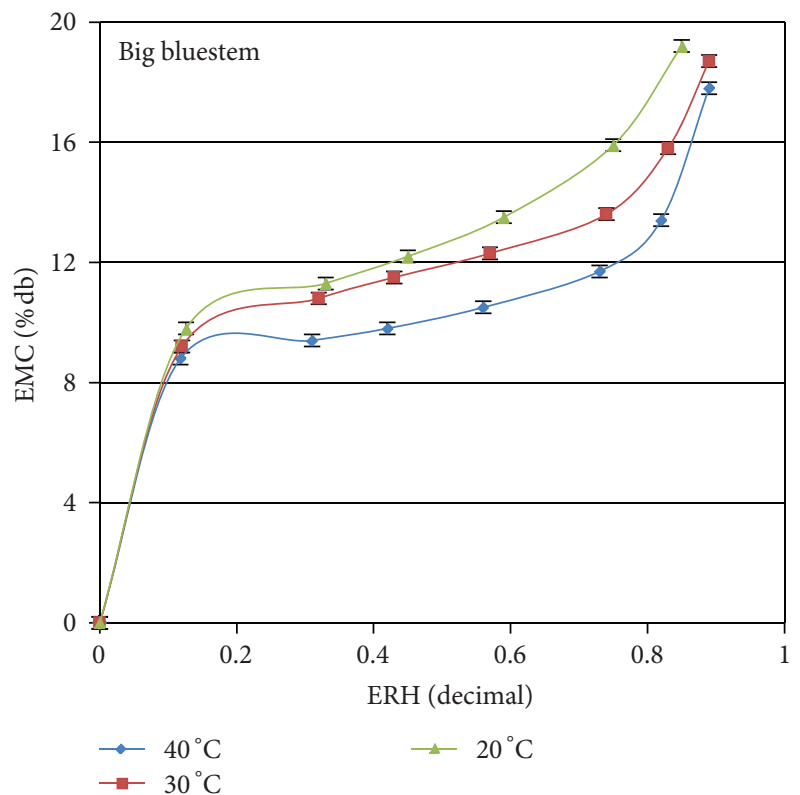

(b)

FIGURE 1: Moisture sorption of corn stover and big bluestem at indicated relative humidities and temperatures.

corn stover and big bluestem data; so this model will not be considered further. In this study, F-statistic value should make a better model performance parameter due to wide variation in the $F$-statistic values of the models. Considering $F$-statistic value, modified Halsey model had the highest for both the feedstocks and the second best was modified Oswin model. According to Wang and Brennan [69], a model can be acceptable if $E_{m}$ values are below $10 \%$, and based on this criterion, all the models are good except for modified GAB. However, other statistical parameters should be considered for proper selection of a model. As observed in Table 4, statistical parameters such as F-statistic, $E_{m}, E_{s}$, and $R^{2}$ followed a similar pattern among models and feedstocks. In general, the lower are the values of $E_{m}$ and
$E_{s}$, and the higher are the values of $R^{2}$ and the better is the goodness of fit. The coincidence of these parameters also indicates modified Halsey as the best and modified Oswin as the second best performing model for corn stover and big bluestem. Modified Chung-Pfost, modified Henderson, and modified GAB models did not perform well based on the criteria considered, and this observation was in agreement with Igathinathane et al. [31] and Nilsson et al. [12].

The next logical step in a model selection is to look into the residual plots of EMC versus ERH. Residual plots of modified Oswin, modified Halsey, modified Henderson, and modified Chung-Pfost for corn stover and big bluestem are shown in Figures 2 and 3, respectively. Among the models, modified Halsey and modified Oswin exhibited a fairly 


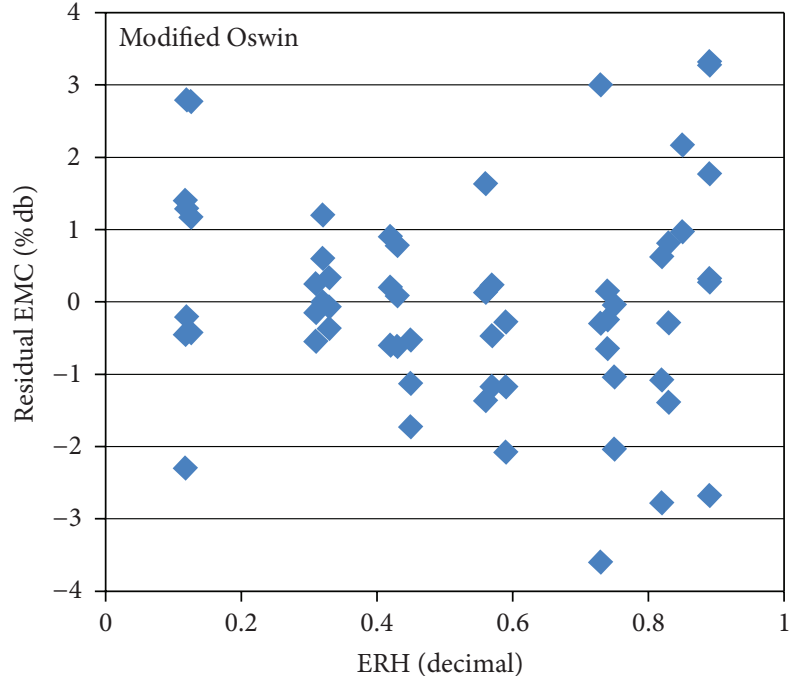

(a)

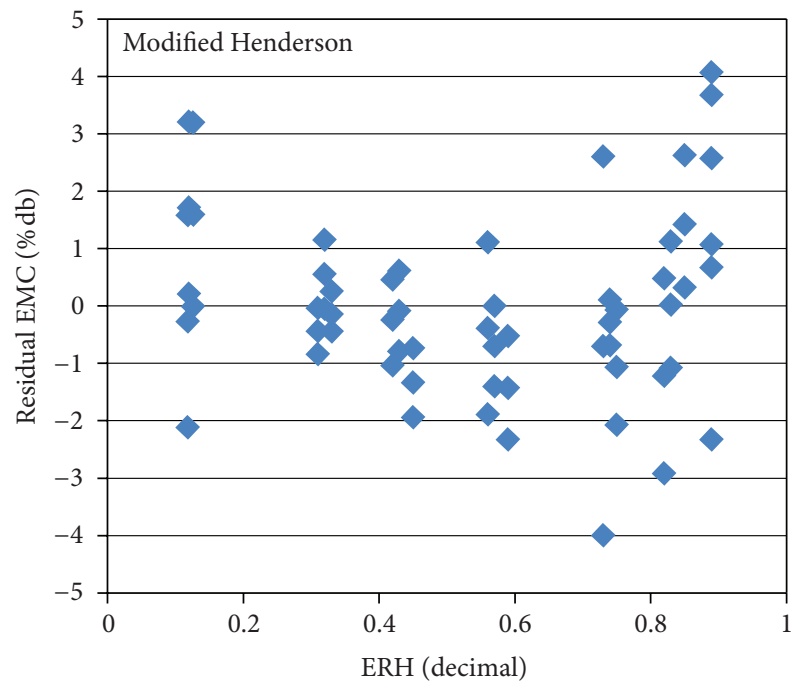

(c)

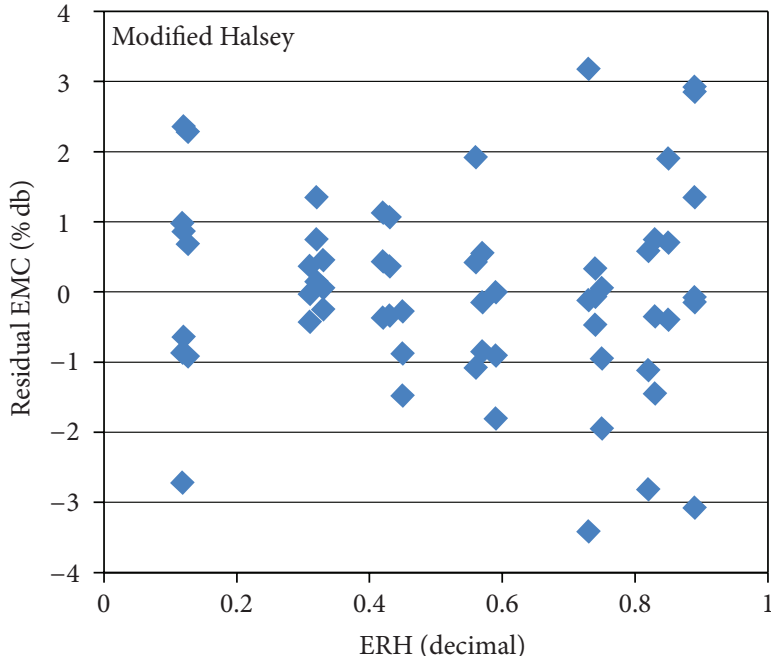

(b)

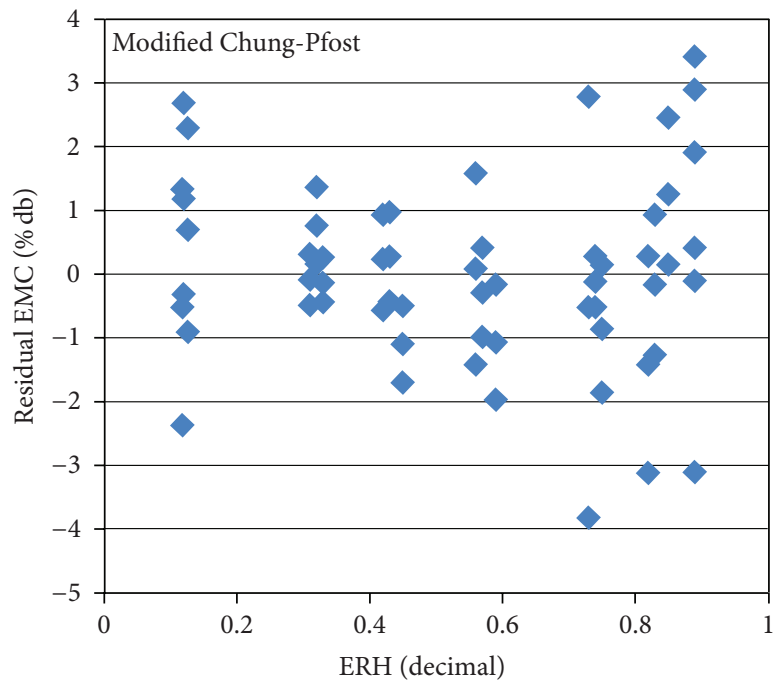

(d)

FIgURE 2: Residual plots of the fitted isotherm equations for the moisture isotherm data of corn stover at temperatures 20 to $40^{\circ} \mathrm{C}$.

random distribution for both feedstocks when compared to modified Henderson and modified Chung-Pfost models. In addition to $F$-statistic, $E_{m}, E_{s}$, and $R^{2}$ values, residual plots also confirm modified Halsey as the best model for corn stover and big bluestem, and the second best model was modified Oswin for corn stover. In another study, a similar model selection was reported for switchgrass and prairie cord grass [64]. Nilsson et al. [12] also reported modified Halsey as the best model for flax and reed canary grass whereas modified Oswin as best model for hemp. The first and second models observed in this study were in reverse order of Igathinathane et al. [31]. Arabhosseini et al. [7] found modified Oswin as suitable model to describe the isotherm relation for miscanthus leaves and stem. Colley et al. [34] observed that modified Chung-Pfost model was the best and modified Oswin was the second best model predicted EMC of switchgrass pellets. According to ASAE standard D245.5 [70], modified Chung-Pfost model predicted the EMC of barely starw. In contrast to the previous studies including the current study, Duggal and Muir [30] reported modified Henderson as suitable model for wheat straw based on standard error of the estimate, and Stencl et al. [33] also reported modified Henderson as the best model for moisture adsorption and desorption of amaranthus stems. Similarly, Stencl and Homola [43] found that Henderson equation was the best model for red clover leaves, and Oswin equation was best for red clover stems.

3.3. Prediction of EMC by Modified Halsey and Modified Oswin Models. The best and second best models were used for generating moisture isotherm of corn stover and big bluestem. Figure 4 shows observed and predicted EMC at 


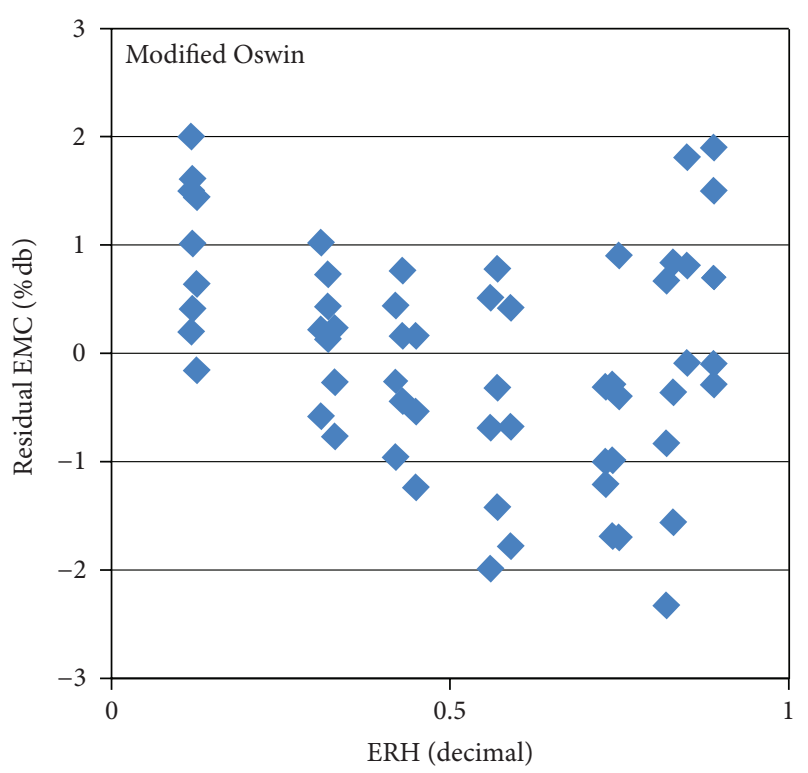

(a)

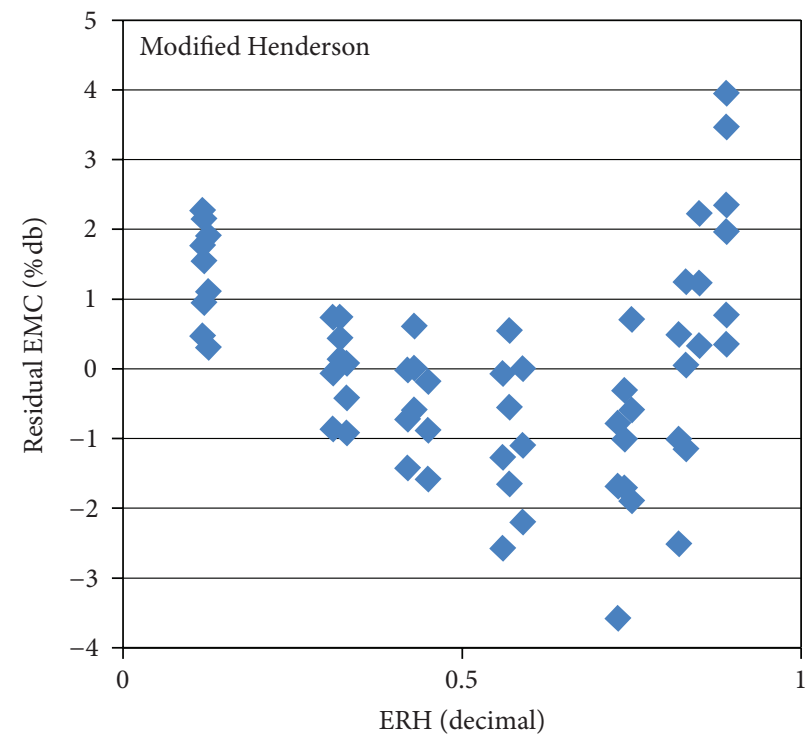

(c)

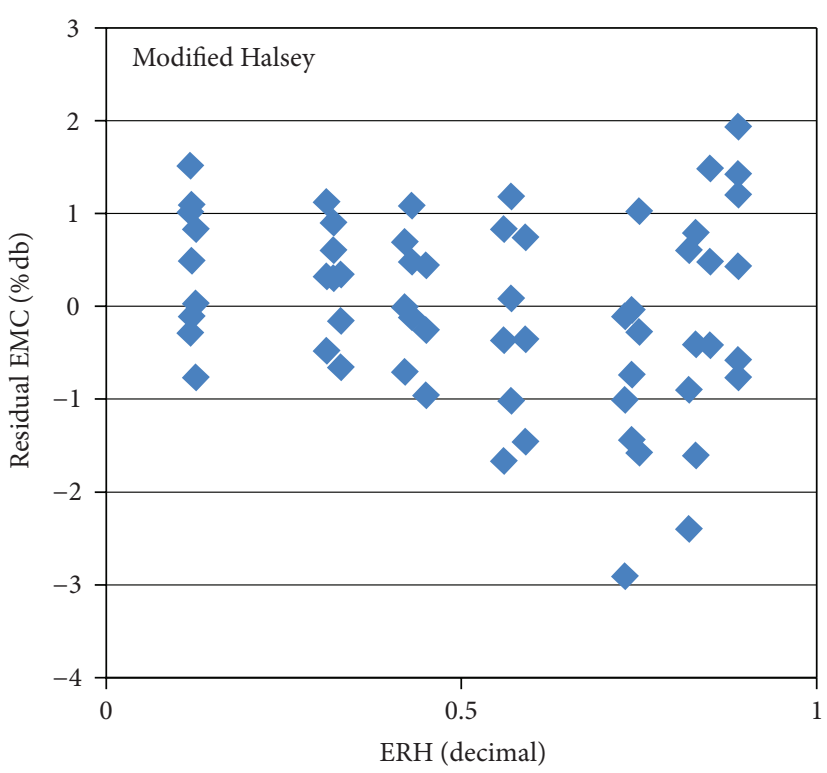

(b)

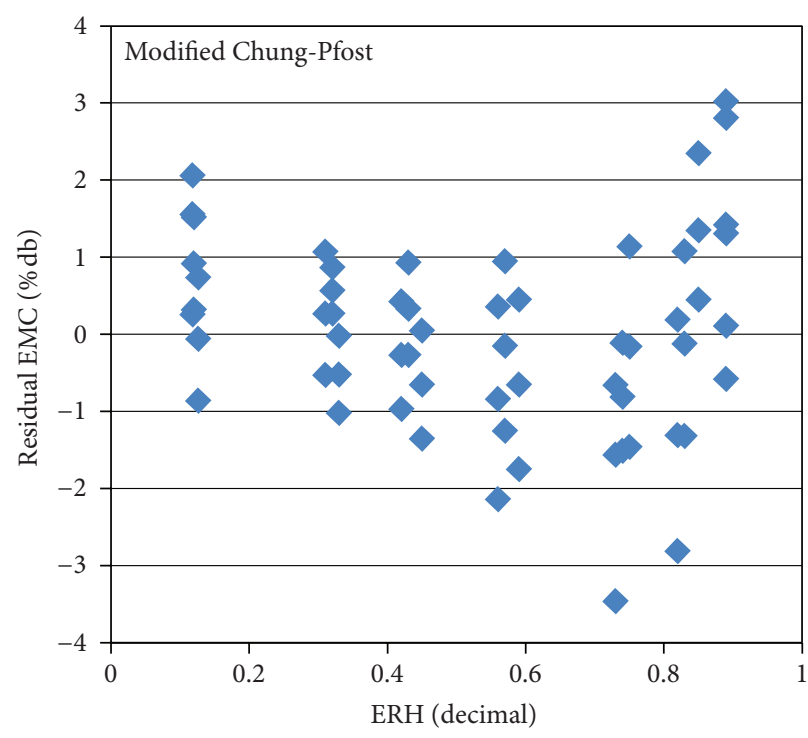

(d)

FIgURE 3: Residual plots of the fitted isotherm equations for the moisture isotherm data of big bluestem at temperatures 20 to $40^{\circ} \mathrm{C}$.

different temperatures $\left(20,30\right.$, and $\left.40^{\circ} \mathrm{C}\right)$. The closeness of observed EMC data (points) and predicted EMC (line) confirms the goodness of model fit for both feedstocks. As seen from these figures, model predicted isotherms follow type II isotherm, which was in agreement with flax straw, reed canary grass, hemp stalk, selected corn stover components, miscanthus leaves and stem, switchgrass, and prairie cord grass $[7,12,31,64]$. A common feature in food material is a sharp increase in EMC greater than an ERH of 0.8 [31], which can be visualized in Figure 4 for corn stover and big bluestem, respectively. When comparing the three temperatures at constant $\mathrm{RH}$, it can be seen that the EMC increases with decreasing temperature. From Figure 4, the predicted isotherms show a good fit of modified Halsey for corn stover and big bluestem, and the arrangement of curves also shows that increase in temperature decreased EMC. Considering the moisture content limit reported for longterm storage by Arabhosseini et al. [7], these feedstocks can be stored up to an ERH of 0.75 within the temperature range studied.

\section{Conclusion}

EMCs of corn stover and big bluestem were determined at three different temperatures with wide range of $\mathrm{RH}$. The observed minimum and maximum EMC values were 8.0 and 8.8 and 19.6 and $19.2 \% \mathrm{db}$ for corn stover and big bluestem, 


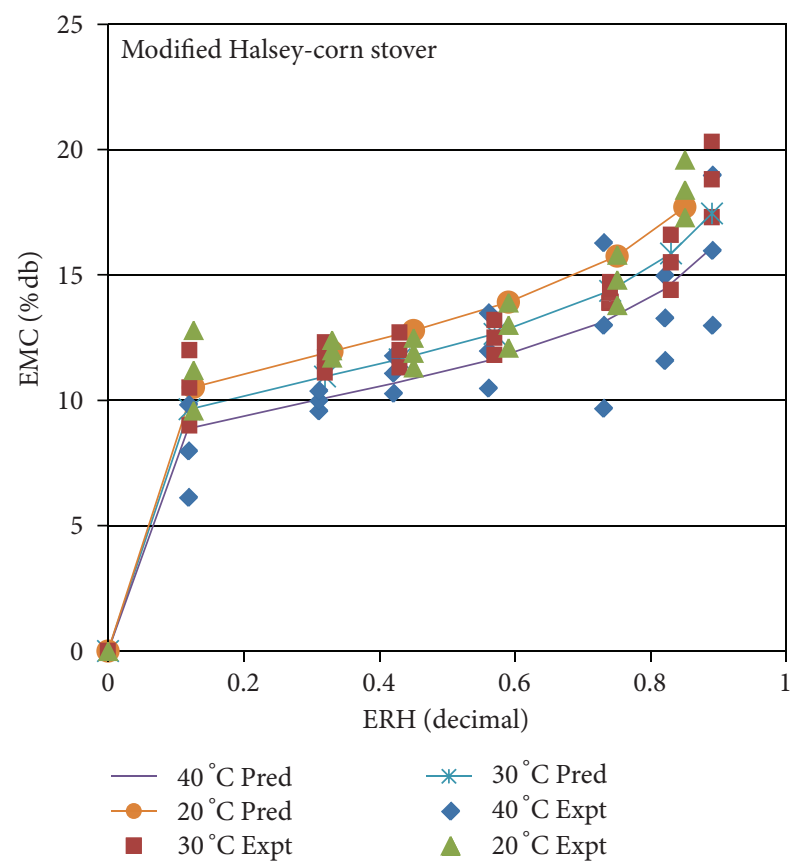

(a)

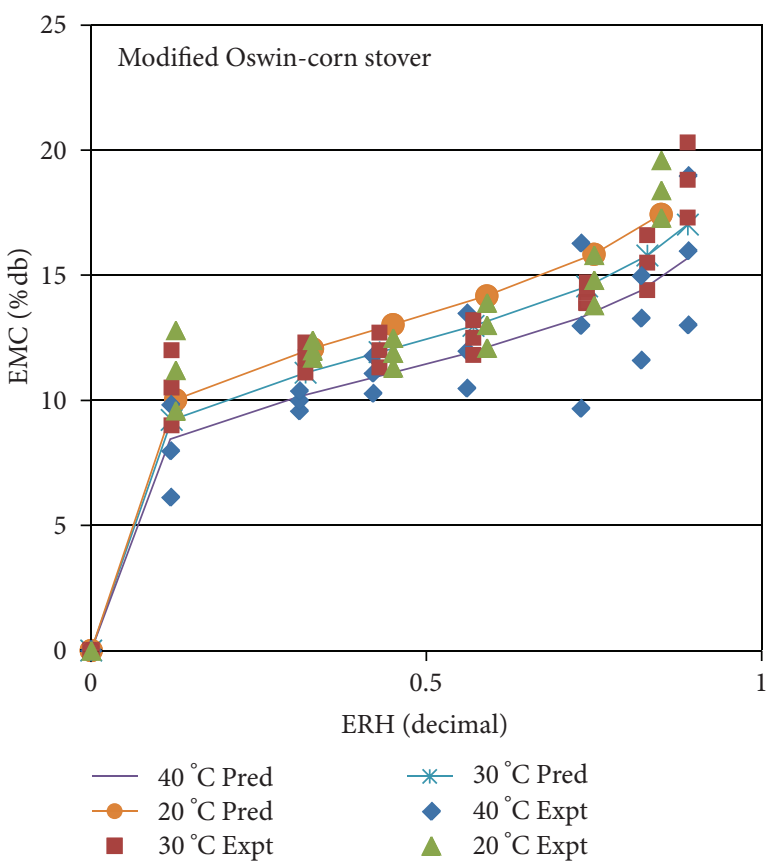

(b)

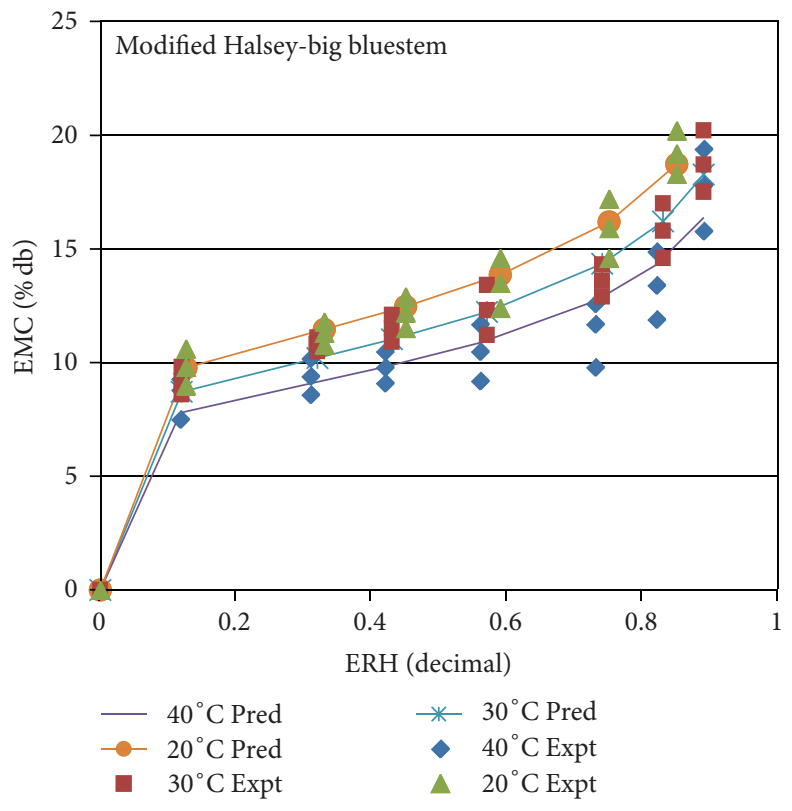

(c)

Figure 4: Comparison between observed and modified Halsey and modified Oswin equations predicted sorption isotherms of corn stover and big bluestem at indicated temperatures (Expt: experimental: Pred; predicted).

respectively. Corn stover had a higher EMC than that of big bluestem at high $\mathrm{RH}$ across the temperature. Among the models applied to fit experimental data of corn stover and big bluestem, modified Halsey model fits very well followed by modified Oswin model. The constants of these equations can be used to estimate the EMC of these feedstocks within the temperature range.

\section{Nomenclature}

Symbols

df: Degree of freedom

$E_{m}$ : Mean relative percent error

$E_{s}$ : Standard error 
$N$ : Number of data points

$R^{2}$ : Coefficient of determination

$Y$ : Experimental equilibrium moisture content $\%(\mathrm{db})$

$\widehat{Y}$ : Predicted equilibrium moisture content $\%(\mathrm{db})$

$\%$ : Percentage

${ }^{\circ} \mathrm{C}$ : Degree Celsius.

Abbreviations

ASAE: American Society of Agricultural Engineers

ASABE: American Society of Agricultural and Biological Engineers

$\mathrm{db}: \quad$ Dry basis

ERH: Equilibrium relative humidity

EMC: Equilibrium moisture content

exp: Experimental

GAB: Guggenheim-Anderson-deBoer

m: $\quad$ Metre

mm: Millimetre

NLIN: Nonlinear

NREL: National Renewable Research Laboratory

Prd: $\quad$ Predicted

RH: Relative humidity

SS: $\quad$ Sum of squares.

\section{Acknowledgments}

This research was supported by funding from the Agricultural Experiment Station and North Central Sun Grant Center at South Dakota State University through a grant provided by the US Department of Transportation, Office of the Secretary (Grant no. DTOS59-07-G-00054).

\section{References}

[1] A. Demirbas, "Emission characteristics of gasohol and diesohol," Energy Sources, vol. 31, no. 13, pp. 1099-1104, 2009.

[2] L. R. Lynd, W. H. Van Zyl, J. E. McBride, and M. Laser, "Consolidated bioprocessing of cellulosic biomass: an update," Current Opinion in Biotechnology, vol. 16, no. 5, pp. 577-583, 2005.

[3] R. D. Perlack, L. L. Wright, A. F. Turhollow, R. L. Graham, B. J. Stokes, and D. C. Erbach, "Biomass as feedstock for a bioenergy and bioproducts industry: the technical feasibility of a billionton annual supply," 2005, http://www.osti.gov/bridge.

[4] J. G. Jung and K. P. Vogel, "Lignification of switchgrass (Panicum virgatum) and big bluestem (Andropogon gerardii) plant parts during maturation and its effect on fiber degradability," Journal of the Science of Food and Agriculture, vol. 59, no. 2, pp. 169-176, 1992.

[5] P. G. Jefferson, W. P. McCaughey, K. May, J. Woosaree, and L. McFarlane, "Potential utilization of native prairie grasses from western Canada as ethanol feedstock," Canadian Journal of Plant Science, vol. 84, no. 4, pp. 1067-1075, 2004.
[6] P. J. Weimer and T. L. Springer, "Fermentability of eastern gamagrass, big bluestem and sand bluestem grown across a wide variety of environments," Bioresource Technology, vol. 98, no. 8, pp. 1615-1621, 2007.

[7] A. Arabhosseini, W. Huisman, and J. Müller, "Modeling of the equilibrium moisture content (EMC) of Miscanthus (Miscanthus $\times$ giganteus)," Biomass and Bioenergy, vol. 34, no. 4, pp. 411$416,2010$.

[8] C. Igathinathane, A. R. Womac, L. O. Pordesimo, and S. Sokhansanj, "Mold appearance and modeling on selected corn stover components during moisture sorption," Bioresource Technology, vol. 99, no. 14, pp. 6365-6371, 2008.

[9] A. Assarsson, "Some reactions during chip storage and how to control them," Pulp and Paper Magazine of Canada, vol. 70, no. 18, pp. 74-79, 1969.

[10] J. Nurmi, "The storage of logging residue for fuel," Biomass and Bioenergy, vol. 17, no. 1, pp. 41-47, 1999.

[11] R. N. Singh, "Equilibrium moisture content of biomass briquettes," Biomass and Bioenergy, vol. 26, no. 3, pp. 251-253, 2004.

[12] D. Nilsson, B. Svennerstedt, and C. Wretfors, "Adsorption equilibrium moisture contents of flax straw, hemp stalks and reed canary grass," Biosystems Engineering, vol. 91, no. 1, pp. 3543, 2005.

[13] A. Chakraverty, Post Harvest Technology of Cereals, Pulses and Oil Seeds, Culcutta: Oxford \& IBH Publishing Company, 3rd edition, 1981.

[14] C. Skaar, Wood Water Relations, Springer, New York, NY, USA, 1988.

[15] I. D. Hartley and S. Avramidis, "Water clustering phenomenon in two softwoods during adsorption and desorption processes," Journal of Wood Science, vol. 13, no. 4, pp. 467-472, 1994.

[16] D. Choudhury, J. K. Sahu, and G. D. Sharma, "Moisture sorption isotherms, heat of sorption and properties of sorbed water of raw bamboo (Dendrocalamus longispathus) shoots," Industrial Crops and Products, vol. 33, no. 1, pp. 211-216, 2011.

[17] N. Arslan and H. Toğrul, "Moisture sorption isotherms for crushed chillies," Biosystems Engineering, vol. 90, no. 1, pp. 4761, 2005.

[18] R. Moreno, G. Antol'ın, A. Reyes, and P. Alvarez, "Drying characteristics of forest biomass particles of Pinus radiata," Biosystems Engineering, vol. 88, no. 1, pp. 105-115, 2004.

[19] J. Jorgenson, P. Gilman, and A. Dobos, "Technical manual for the SAM biomass power generation model," Tech. Rep. NREL/TP-6A20-52688, National Renewable Energy Laboratory Golden, Colo, USA.

[20] N. A. Aviara, O. O. Ajibola, O. A. Aregbesola, and M. A. Adedeji, "Moisture sorption isotherms of sorghum malt at 40 and $50^{\circ} \mathrm{C}$," Journal of Stored Products Research, vol. 42, no. 3, pp. 290-301, 2006.

[21] S. Rahman, "Water activity and sorption properties of food," in Food Properties Handbook, pp. 1-86, CRC Press, Boca Raton, Fla, USA, 1995.

[22] S. Arnosti, J. T. Freire, D. J. M. Sartori, and M. A. S. Barrozo, "Equilibrium moisture content of Brachiaria brizantha," Seed Science and Technology, vol. 27, no. 1, pp. 273-282, 1999.

[23] L. N. Bell and T. P. Labuza, Moisture Sorption Practical Aspects of Isotherm Measurement and Use, American Association of Cereal Chemists, St. Paul, Minn, USA, 2000.

[24] S. Gal, "Recent developments in techniques for obtaining complete sorption isotherms," in Water Activity: Influence on Food Quality, L. B. Rockland and G. F. Stewart, Eds., Academic Press, New York, NY, USA, 1981. 
[25] W. E. L. Speiss and W. Wolf, "Critical evaluation of methods to determine moisture sorption isotherms," in Water Activity, Theory and Applications To Foods, L. B. Rockland and L. R. Beuchat, Eds., pp. 215-233, Marcel Dekker, New York, NY, USA, 1987.

[26] P. P. Lewicki and W. Pomaranska-Lazuka, "Errors in static desiccator method of water sorption isotherms estimation," International Journal of Food Properties, vol. 6, no. 3, pp. 557563,2003

[27] C. C. Chen and R. V. Morey, "Equilibrium relativity humidity (ERH) relationships for yellow-dent corn," Transactions of the American Society of Agricultural Engineers, vol. 32, no. 3, pp. 999-1006, 1989.

[28] F. J. Zink, "Equilibrium moistures of some hays," Agricultural Engineering, vol. 16, no. 11, pp. 451-452, 1935.

[29] S. T. Dexter, W. H. Sheldon, and D. I. Waldron, "Equilibrium moisture content of alfalfa hay," Agricultural Engineering, vol. 28, no. 7, pp. 295-296, 1947.

[30] A. K. Duggal and W. E. Muir, "Adsorption equilibrium moisture content of wheat straw," Journal of Agricultural Engineering Research, vol. 26, no. 4, pp. 315-320, 1981.

[31] C. Igathinathane, A. R. Womac, S. Sokhansanj, and L. O. Pordesimo, "Sorption equilibrium moisture characteristics of selected corn stover components," Transactions of the American Society of Agricultural Engineers, vol. 48, no. 4, pp. 1449-1460, 2005.

[32] Z. Pakowski, B. Krupinska, and R. Adamski, "Prediction of sorption equilibrium both in air and superheated steam drying of energetic variety of willow Salix viminalis in a wide temperature range," Fuel, vol. 86, no. 12-13, pp. 1749-1757, 2007.

[33] J. Stencl, M. Fajman, P. Sedlak, B. Janstova, J. Kleparnik, and J. Stencl Jr., "Sorption characteristics of amaranthus stems under storage conditions and water activity prediction," Bioresource Technology, vol. 101, no. 23, pp. 9395-9398, 2010.

[34] Z. Colley, O. O. Fasina, D. Bransby, and Y. Y. Lee, "Moisture effect on the physical characteristics of switchgrass pellets," Transactions of the ASABE, vol. 49, no. 6, pp. 1845-1851, 2006.

[35] I. D. Hartley and L. J. Wood, "Hygroscopic properties of densified softwood pellets," Biomass and Bioenergy, vol. 32, no. 1, pp. 90-93, 2008.

[36] O. O. Fasina, "Physical properties of peanut hull pellets," Bioresource Technology, vol. 99, no. 5, pp. 1259-1266, 2008.

[37] K. Theerarattananoon, F. Xu, J. Wilson et al., "Physical properties of pellets made from sorghum stalk, corn stover, wheat straw, and big bluestem," Industrial Crops and Products, vol. 33, no. 2, pp. 325-332, 2011.

[38] Y. Soysal and S. Oztekin, "Equilibrium moisture content equations for some medicinal and aromatic plants," Journal of Agricultural Engineering Research, vol. 74, no. 3, pp. 317-324, 1999.

[39] C. C. Chen and R. V. Morey, "Comparison of four EMC/ERH equations," Transactions of the American Society of Agricultural Engineers, vol. 32, no. 3, pp. 983-990, 1989.

[40] D. W. Sun and J. L. Woods, "Moisture content/relative humidity equilibrium relationship of wheat-a review," Drying Technology, vol. 11, no. 7, pp. 1523-1551, 1993.

[41] D. W. Sun and J. L. Woods, "The selection of sorption isotherm equations for wheat based on the fitting of available data," Journal of Stored Products Research, vol. 30, no. 1, pp. 27-43, 1994.
[42] D. W. Sun and C. Byrne, "Selection of EMC/ERH isotherm equations for rapeseed," Journal of Agricultural Engineering Research, vol. 69, no. 4, pp. 307-315, 1998.

[43] J. Stencl and P. Homola, "Water sorption isotherms of leaves and stems of Trifolium pratense L.," Grass and Forage Science, vol. 55, no. 2, pp. 159-165, 2000.

[44] C. A. S. Hill, A. Norton, and G. Newman, "The water vapor sorption behavior of natural fibers," Journal of Applied Polymer Science, vol. 112, no. 3, pp. 1524-1537, 2009.

[45] C. A. S. Hill, A. Norton, and G. Newman, "The water vapor sorption behavior of flax fibers-analysis using the parallel exponential kinetics model and determination of the activation energies of sorption," Journal of Applied Polymer Science, vol. 116, no. 4, pp. 2166-2173, 2010.

[46] Y. Xie, C. A. S. Hill, Z. Jalaludin et al., "The dynamic water vapour sorption behaviour of natural fibres and kinetic analysis using the parallel exponential kinetics model," Journal of Materials Science, vol. 46, no. 2, pp. 479-489, 2011.

[47] Y. Xie, C. A. S. Hill, Z. Xiao, Z. Jalaludin, H. Militz, and C. Mai, "Water vapor sorption kinetics of wood modified with glutaraldehyde," Journal of Applied Polymer Science, vol. 117, no. 3, pp. 1674-1682, 2010.

[48] Y. Xie, C. A. S. Hill, Z. Xiao, C. Mai, and H. Militz, "Dynamic water vapour sorption properties of wood treated with glutaraldehyde," Wood Science and Technology, vol. 45, no. 1, pp. 49-61, 2011.

[49] A. N. Papadopoulos, "Moisture adsorption isotherms of two esterified Greek hardwoods," Holz als Roh- und Werkstoff, vol. 63, no. 2, pp. 123-128, 2005.

[50] R. Wimmer and T. Schmid, "Dynamic vapor sorption of analyses of wood-a new approach to classical problems," in Proceedings of the International Convention of Society of Wood Science and Technology and United Nations Economic Commission for Europe-Timber Committee, Geneva, Switzerland, October 2010.

[51] A. N. Papadopoulos and C. A. S. Hill, "The sorption of water vapour by anhydride modified softwood," Wood Science and Technology, vol. 37, no. 3-4, pp. 221-231, 2003.

[52] G. I. Mantanis and A. N. Papadopoulos, "The sorption of water vapour of wood treated with a nanotechnology compound," Wood Science and Technology, vol. 44, no. 3, pp. 515-522, 2010.

[53] Moisture Measurement-Forages ASAE Standards S358. 2, ASABE, St. Joseph, Mich, USA, 2003.

[54] A. Sluiter, R. Ruiz, C. Scarlata, J. Sluiter, and D. Templeton, "Determination of Extractives in Biomass," Tech. Rep. NREL/TP-510-42619, National Renewable Energy Laboratory, Golden, Colo, USA, 2005.

[55] H. M. Spencer, "Laboratory methods for maintaining constant humidity," in International Critical Tables of Numerical Data, Physics, Chemistry, and Technology 1, pp. 67-68, McGraw-Hill, New York, NY, USA, 1926.

[56] C. D. Hodgman, Handbook of Chemistry and Physics, CRC, Cleveland, Ohio, USA, 1955.

[57] L. Greenspan, "Humidity fixed points of binary saturated aqueous solutions," Journal of Research of the National Bureau of Standards A, vol. 81, no. 1, pp. 89-96, 1977.

[58] C. Van den Berg, "Water activity," in Concentration and Drying of Foods, Q. McCarthy, Ed., pp. 11-36, Elsevier Applied Science Publisher, London, UK, 1985.

[59] H. B. Pfost, S. G. Mourer, D. S. Chung, and G. A. Milliken, "Summarizing and reporting equilibrium moisture data for grains," ASAE Paper No. 85-3512, 1976. 
[60] ASAE D245.5, Moisture Relationship of Plant-Based Agricultural Products, American Society of Agricultural Engineers, St. Joseph, Mich, USA, 3rd edition, 1996.

[61] W. Wolf, W. E. L. Speiss, and G. Jung, "Standardization of isotherm measurements (cost project 90 and 90 bis)," in Properties of Water in Foods in Relation To Quality and Stability, D. Simantos and J. L. Multon, Eds., pp. 661-679, Martinus Nijhoff Publishers, Dordrecht, The Netherlands, 1985.

[62] C. J. Lomauro, A. S. Bakshi, and T. P. Labuza, "Evaluation of food moisture sorption isotherm equations part II: Milk, coffee, tea, nuts, oilseeds, spices and starchy foods," Food Science and Technology, vol. 18, no. 2, pp. 118-124, 1985.

[63] D. S. Jayas and G. Mazza, "Comparison of five three-parameter equations for the description of adsorption data of oats," Transactions American Society of Agricultural Engineers, vol. 36, no. 1, pp. 119-125, 1993.

[64] C. Karunanithy, Muthukumarappan, and A. Doenpudi, "Moisture adsorption characteristics of switchgrass and prairie cord grass," Fuel, vol. 103, pp. 171-178, 2012.

[65] R. C. Brown, Thermochemical Process of Biomass: Conversion Into Fuels. Chemicals and Power, John Wiley \& Sons, 2011.

[66] W. Yan, T. C. Acharjee, C. J. Coronella, and V. R. Vásquez, “Thermal pretreatment of lignocellulosic biomass," Environmental Progress and Sustainable Energy, vol. 28, no. 3, pp. 435-440, 2009.

[67] Y. Soysal and S. Öztekin, "Comparison of seven equilibrium moisture content equations for some medicinal and aromatic plants," Journal of Agricultural Engineering Research, vol. 78, no. 1, pp. 57-63, 2001.

[68] R. Viswanathan, D. S. Jayas, and R. B. Hulasare, "Sorption isotherms of tomato slices and onion shreds," Biosystems Engineering, vol. 86, no. 4, pp. 465-472, 2003.

[69] N. Wang and J. G. Brennan, "Moisture sorption isotherm characteristics of potatoes at four temperatures," Journal of Food Engineering, vol. 14, no. 4, pp. 269-287, 1991.

[70] ASAE Standards, "Moisture relationships of plant-based agricultural products," American Society of Agricultural Engineers, vol. 245, pp. 512-528, 1999. 


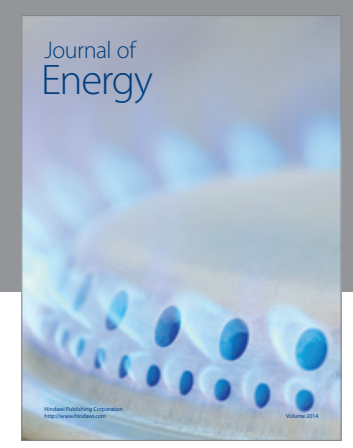

Journal of

Industrial Engineering
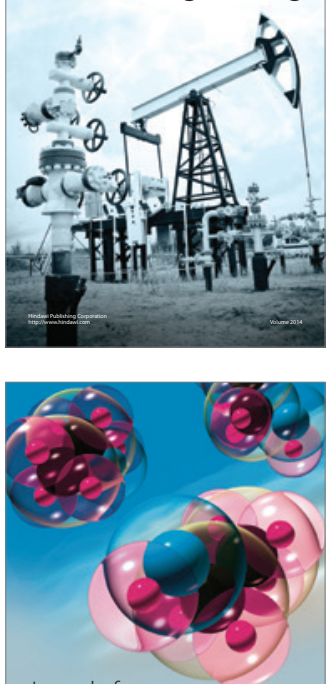

Fuels
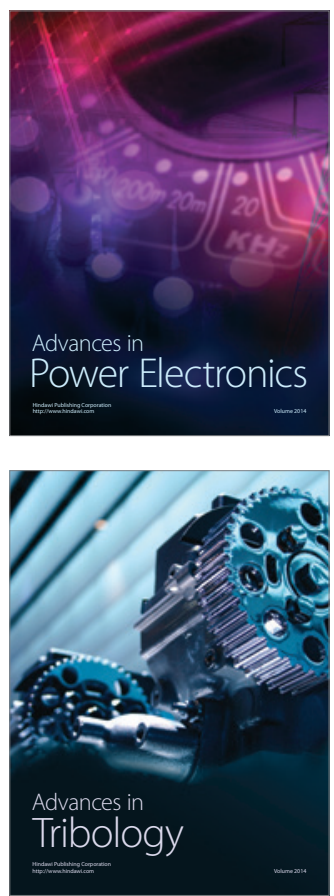

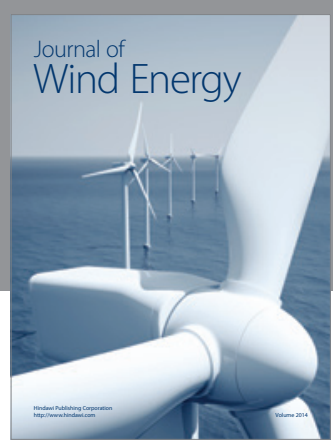

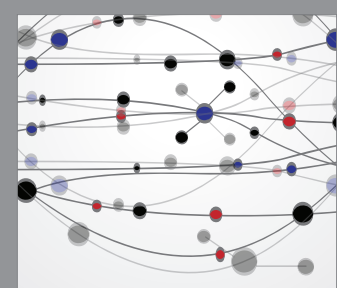

The Scientific World Journal

Submit your manuscripts at http://www.hindawi.com

Journal of

Structures
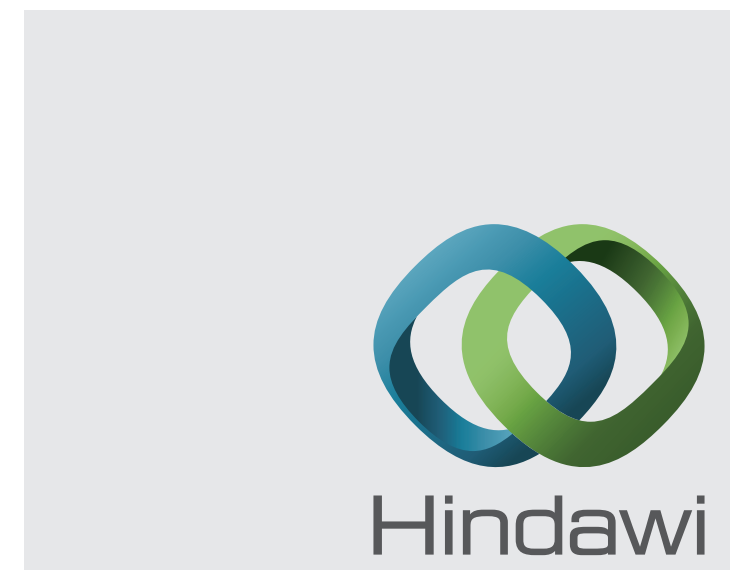

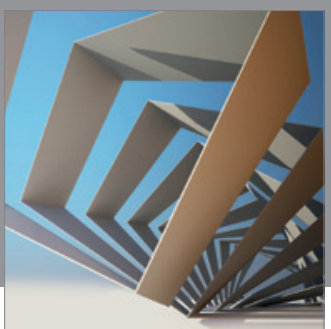

Rotating

Machinery
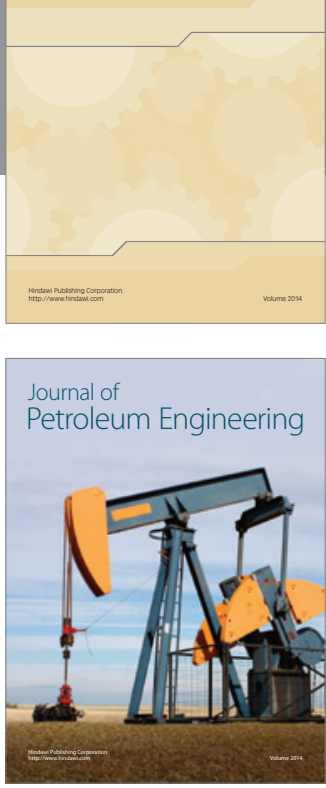

Journal of

Solar Energy
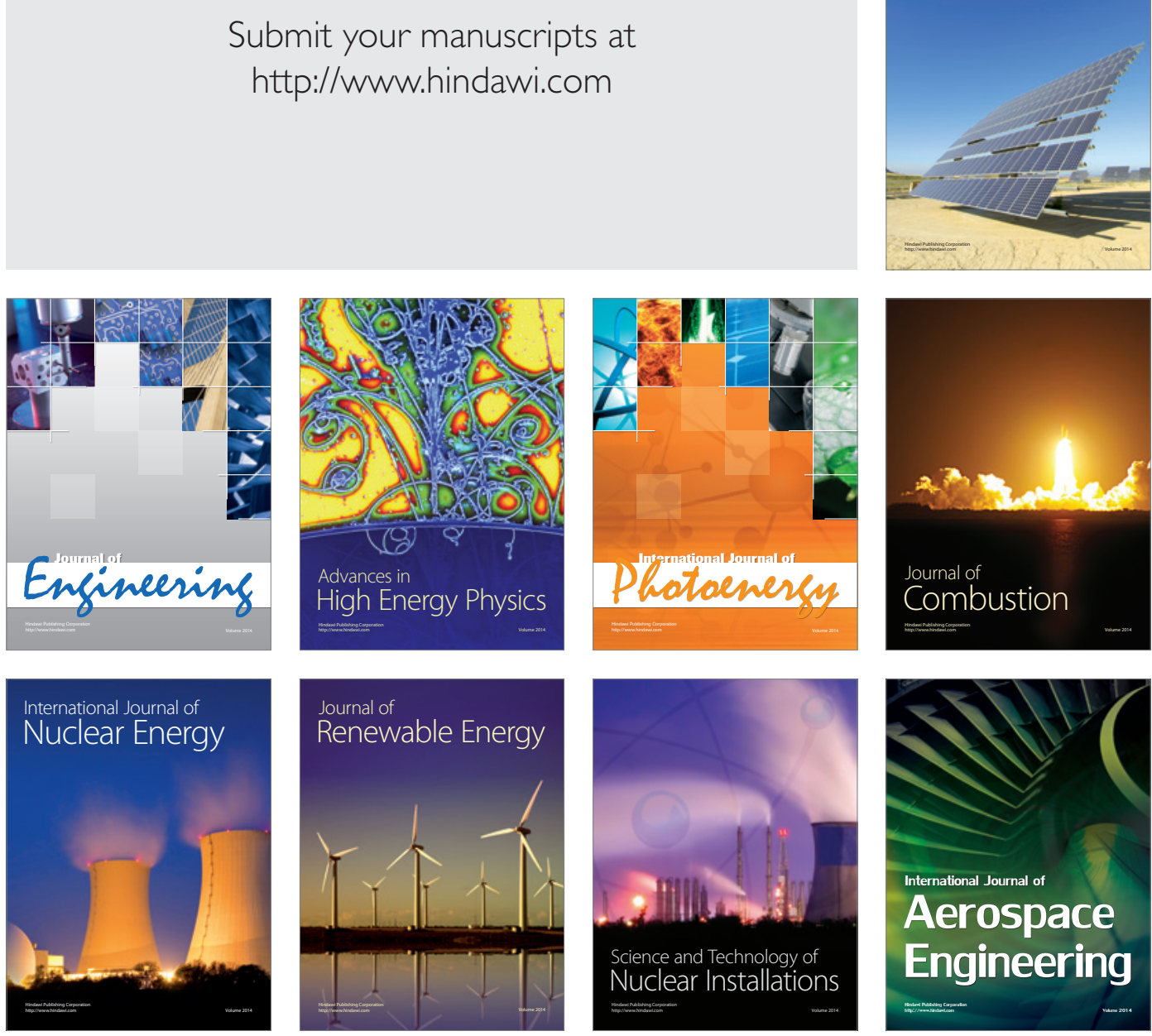